\title{
I Dinámica política y tradición constitucio- nal: la reforma de 1949 en la provincia de Santa Fe
}

Darío Macor ${ }^{1}$

La constitución vendría a ser para nuestros males, lo que aquellas tisanas que traen, envolviendo el frasco que las contiene, la instrucción para enseñar la manera de usarlos.

Domingo F. Sarmiento

\section{I.}

La Constitución Nacional de 1853 ocupó un lugar central en las representaciones colectivas con que los argentinos definían su lugar en el mundo a lo largo de la segunda mitad del siglo XIX y primeras décadas del XX. Esta importancia del texto constitucional original, ayuda a explicar su permanencia como dispositivo de organización de las principales instituciones del Estado. Durante casi un siglo la Constitución sólo sufre reformas muy puntuales e instrumentales (1860, 1866 y 1898); recién a mediados del siglo XX se produce una reforma ambiciosa.

En 1949, a tres años de haber asumido el gobierno, el peronismo emprende la reforma de la Constitución, con el objetivo de adaptar el sistema institucional al nuevo orden político y social. La reforma propuesta es parte de un dispositivo mayor de centralización y homogeneización del poder, impuesto desde la presidencia de la nación, y opera como una pieza importante en la construcción del imaginario político oficial, al dotar al peronismo de ese carácter fundacional que reivindicaba para sí.

1- Historiador, Profesor Titular de Universidad Nacional del Litoral e Investigador del CONICET. Universidad Nacional del Litoral: 9 de julio 3563, Ciudad de Santa Fe, Argentina (CP. 3000). E-mail: dmacor@fhuc.unl.edu.ar. Una primera versión de este trabajo fue presentado en la IX Jornadas Interescuelas/departamentos de Historia, Córdoba, septiembre de 2003. 
¿Cuál es el sentido y la oportunidad que tienen los proyectos constitucionales, en especial las reformas ambiciosas como la que impulsa el peronismo? ¿Se trata de adecuar la ley a los cambios ocurridos en la sociedad o, por el contrario, las reformas pretenden diseñar un horizonte que resuma las aspiraciones de una sociedad? O, para decirlo en la clave de Natalio Botana y Ana María Mustapic, ¿las reformas constitucionales se plantean como una anticipación para resolver cuestiones futuras que el legislador prevé o como un instrumento de resolución de un conflicto presente? (Botana y Mustapic 1991: 49).

Para el Sarmiento del epígrafe y los que con él estaban lanzados a la aventura de invención de una nación, la función anticipatoria y luego pedagógica de la Constitución resultaba fundamental en la dura empresa de asegurar un orden estatal. El proyecto constitucional de 1949 se inscribe en otro registro. Un registro que da cuenta de los problemas y contradicciones del proceso de construcción de la identidad peronista, remitiendo, por un lado, a las presunciones fundacionales del oficialismo, y por otro, a los problemas del consenso político necesario para alejar al proyecto constitucional del riesgo de transformarse en un mero instrumento de dominación del gobierno.

A partir de los interrogantes y problemas planteados, en este trabajo nos concentraremos en el análisis de la reforma de la Constitución de la provincia de Santa Fe, en 1949, en cumplimiento de lo dispuesto por la Asamblea Constituyente nacional que reformara la Constitución de 1853. En tal sentido, nos interesa observar si se trata de una mera adaptación a la nueva Carta nacional o pueden apreciarse márgenes de autonomía, sobre todo en consideración de la tradición constitucional local que remite a las Constituciones de 1900 y 1921, ambas desligadas de un proceso reformista nacional. En ese contexto revisaremos especialmente los temas que aparecen como ejes de las discusiones en torno a la reforma, atendiendo a los actores que intervienen y los ámbitos en los que tienen lugar los debates; tratando de desentrañar, a la par, los principales rasgos de la relación oficialismo / oposición en ese proceso.

En esa relación, nos interesa observar los consensos logrados en torno al proyecto constitucional impulsado por el gobierno. De por sí importantes en el juego político en general, los consensos resultan fundamentales en los procesos de reforma constitucional: favorecen la vigencia efectiva de la Constitución, porque al comprometer a la oposición en la toma de decisiones ésta no la percibe como un instrumento de dominación por parte del parti- 
do oficial. De esta manera es posible que una Constitución funcione como "un sistema de legitimidad que opera efectivamente en el tiempo» (Botana y Mustapic 1991: 50).

\section{II.}

La Constitución Nacional sancionada en marzo de 1949, autorizaba en sus disposiciones transitorias, por esa única vez, a las legislaturas provinciales para reformar totalmente las Constituciones locales con el fin de adaptarlas a los principios, declaraciones, derechos y garantías consagrados en ella. ${ }^{2} \mathrm{~A}$ renglón seguido, precisaba las formas y el plazo en que debían hacerlo: en 90 días, contados a partir de la sanción de la Carta nacional, las legislaturas provinciales transformadas en Asambleas Constituyentes debían proceder a las reformas de sus respectivas Constituciones. Para aquellas provincias que al momento no tuvieran legislaturas conformadas, el plazo entraría a correr a partir de su conformación.

En Santa Fe, la situación política se presentaba muy difícil. La provincia había sido intervenida en los primeros días de febrero del año 1949. Una intervención que en principio sólo afecta al poder ejecutivo, pone fin a un largo conflicto gestado al iniciarse el mandato del gobernador Waldino Suárez, en 1946, y atizado, en los años siguientes, por la resistencia del mismo a la pérdida de autonomía en favor de la centralización impuesta desde la nación al gobierno y a la organización partidaria peronista local. ${ }^{3}$ Entre los fundamentos que acompañan el decreto de intervención se señala:

«... los abundantes elementos de juicio recogidos en las más diversas y autorizadas fuentes de información, coincidiendo con las comprobaciones que este gobierno ha venido efectuando desde tiempo atrás, Ilevan a la muy lamentable conclusión de que el PE de Santa Fe no ha sabido o no ha querido cumplir los compromisos asumidos ante el pueblo de la provincia. Son las notas características de su actuación, pasividad y hasta negligencia en el orden administrativo, des-

2- Constitución Nacional de 1949, Disposiciones transitorias, art. $5^{\circ}$.

3- Waldino Suárez dirige desde la gobernación la organización del Partido Obrero de la Revolución (POR), un peronismo local con pretensiones de cierta autonomía con respecto a los dictados del Estado nacional. En 1948 el POR compite en las elecciones del distrito santafesino, siendo derrotado por el Partido Peronista que se mantiene fiel a los dictados del poder nacional. Meses más tarde la dirigencia del POR resuelve disolver la organización (Macor 2002). 
preocupación frente a los problemas de gobierno y a las necesidades de la población, ineficacia para coordinar la acción de sus ministros y dependencias y mantener las buenas relaciones con los otros poderes del Estado. Tendencia a provocar o ahondar crisis gubernativas, indigencias respecto a vicios o corruptelas que estaba en sus manos la obligación de corregir, tanto como el auge extraordinario que ha adquirido el juego de azar en toda la provincia y la venalidad de algunos funcionarios». 4

Con argumentos fuertemente descalificatorios a la gestión ejecutiva provincial, el poder nacional interviene la Provincia como cierre de un conflicto de larga data. Al hacerlo realiza una operación que hace recaer todas las responsabilidades de la gestión local condenada en la figura del gobernador.

«... si bien la Legislatura ha señalado en diversas oportunidades la inacción del PE, así como la deficiencia y fallas de su actuación, no ha dejado de proporcionar en la medida necesaria los instrumentos legales y financieros indispensables para una eficiente acción de gobierno, instrumentos que el poder ejecutivo no ha sabido utilizar para bien de la provincia, demostrando así una falta de colaboración y solidaridad, que sólo él es responsable y, malogrando de tal modo las tareas legislativas que a él le incumbía llevar a su debida ejecución...

... la situación existente en la provincia de Santa Fe ... adquiere de tal modo los contornos de una verdadera subversión institucional que determina a este PE a ejercitar la atribución que los artículos $5^{\circ}$ y $6^{\circ}$ de la Constitución Nacional acuerdan al gobierno federal». ${ }^{5}$

De esa manera, el poder nacional decide resguardar la acción de la legislatura provincial «que en diversas oportunidades ha señalado la inacción del PE...» y "que no ha dejado de proporcionar ... los instrumentos indispensables para la acción de gobierno». El hecho de intervenir sólo al poder ejecutivo, salvando así las otras instituciones y fundamentalmente al poder legislativo es difícil de explicar, sobre todo cuando esta decisión a favor de la legislatura, será revisada a poco andar, como veremos enseguida. Los diarios de la época sugieren que la medida responde a la intención de no perjudicar a los representantes de la provincia en la Convención Constituyente nacional 
que está sesionando al momento de la intervención. ${ }^{6}$ Sin embargo esta explicación resulta insuficiente para explicar lo sucedido, si consideramos que los convencionales constituyentes por la provincia han sido electos para tal fin en las pasadas elecciones de diciembre de 1948, por lo que su legitimidad no depende ni del gobernador ahora depuesto ni de la legislatura aún en ejercicio.

Seguramente la situación al interior del Partido Peronista santafesino no sea ajena a esta medida, aún cuando el intento de un sector del partido por mantener cierta cuota de autonomía haya naufragado en el pasado año con la cancelación de la experiencia del Partido Obrero de la Revolución, dirigido por el gobernador Suárez. Los conflictos y las luchas por los espacios de poder al interior del peronismo local persisten y se traducen en actitudes que pueden parecer por lo menos erráticas en el comportamiento de algunos miembros de la organización. En este clima, días antes de la intervención federal, un grupo de legisladores peticiona ante el ejecutivo nacional por la continuidad del gobernador, pero una vez producida la misma suscriben un documento de apoyo al interventor. En un pasaje de un extenso comunicado emitido por el Partido Demócrata Progresista, ante lo ocurrido en la provincia, se alude con tono irónico al comportamiento de los legisladores del oficialismo:

«... Los legisladores no han tenido otra preocupación que la propia subsistencia. Con 60 pasajes facilitados por el Ministerio de Gobierno para ellos y algunos familiares, viajaron a Buenos Aires con el objeto de pedir por el ex gobernador, pero en el Ministerio del Interior se enteraron que la suerte de éste ya estaba decidida y se les indicó que debían pedir ellos la intervención del PE. Con los mismos pasajes regresaron a Santa Fe y con el mismo fervor revolucionario que fueron a demandar clemencia, pidieron después la decapitación del gobernador. Así es cómo entienden sus deberes y defienden su investidura y la autonomía de la provincia... ya veremos el destino que le espera a esta Legislatura por ahora sobreseída». ${ }^{7}$

6- Diario El Litoral, Santa Fe, 03/02/1949.

7- Comunicado del Partido Demócrata Progresista a raíz de la Intervención federal a la provincia. Diario El Litoral, Santa Fe, 09/02/1949. 
Esta legislatura «sobreseída» lo será por poco tiempo. ${ }^{8}$ A casi dos meses de la intervención al ejecutivo, un decreto ampliará la misma al poder legislativo. Los esfuerzos de algunos legisladores por demostrar una prolija alineación, a partir de comunicados de adhesión al interventor y a las directivas emanadas de las esferas nacionales partidarias, no se traducen inmediatamente en acuerdos para resolver las candidaturas del oficialismo ante las elecciones convocadas por la intervención para normalizar la vida institucional de la provincia. Por otra parte, las disposiciones transitorias de la nueva Constitución Nacional jerarquizan el lugar de las legislaturas locales al autorizar su transformación en Asambleas Constituyentes para la reforma de las Cartas provinciales. En este contexto, el ejecutivo nacional toma los resguardos necesarios para asegurar su control sobre la legislatura santafesina, decidiendo ampliar la intervención federal a ese poder del Estado. La intervención opera como aleccionadora para quienes habían participado -junto con el ex gobernador- de la «aventura» del Partido Obrero de la Revolución, y para los que aún manteniéndose en las filas del partido oficial mostraran algunas mínimas disidencias. Lo es también para la oposición -conformada en la legislatura provincial por el PDP y la UCR- que, con su comportamiento -sobre todo la UCR-, dificulta la conformación de autoridades en la cámara de diputados y se muestra reticente a jurar la nueva Constitución Nacional.

La ampliación del decreto de intervención a la legislatura obliga entonces a reordenar la agenda de las elecciones convocadas, sumando ahora los cargos legislativos. El 8 de mayo de 1949, se celebran las elecciones y los resultados otorgan un amplio triunfo al peronismo, que obtiene 43 de los 60 electores para gobernador, 30 de los 41 diputados y 13 de los 19 senadores. En la nueva legislatura la oposición quedará reducida al radicalismo, ante los magros resultados obtenidos por el PDP. La UCR ha obtenido 17 electores de gobernador, y conforma un bloque legislativo de 11 diputados y 6 senadores consolidándose como la oposición institucional (Macor 2002).

8- El Partido Demócrata Progresista entendía que «... Gobernador, Legislatura y partido oficialista son todos una misma cosa, responsables por igual de lo que ocurre en Santa Fe, y en verdad no podía ser de otro modo ya que se trata, en definitiva, de simples piezas que responden incondicionalmente al mecanismo de la llamada política de la revolución...». Diario El Litoral, Santa Fe, 09/02/1949.

También en el oficialismo se comienza a hablar de la necesidad de hacer extensiva la medida al poder legislativo «por haberse llegado a la conclusión que no puede elegirse un nuevo gobernador con la situación actual de ambas cámaras, sobre cuyos componentes hay abundante documentación en la Casa Rosada que justificaría la medida...». Diario El Litoral, Santa Fe, 23/02/1949. 
Con la puesta en funciones de las autoridades electas, comenzarán a tomarse las primeras medidas para ajustar la Carta constitucional provincial a la nacional. En esa dirección, el gobernador convoca a la legislatura para el mes de julio. La transformación de ambas cámaras en Asamblea Constituyente tiene para la oposición un vicio de origen porque no se respeta lo estipulado en la Constitución provincial de 1900, vigente en ese momento, que fija como procedimiento para la reforma de la Constitución la conformación de una Asamblea Constituyente compuesta por diputados elegidos expresamente para tal fin.

La oposición habla en defensa de la tradición constitucional local y del federalismo frente al sometimiento de la provincia a los dictados del poder nacional. Desde ese lugar, hace una lectura del pasado argentino que legitima sus actuales argumentos a favor de la autonomía de la provincia. "Los derechos de las provincias no deben desconocerse, las provincias son anteriores a la Nación...», y en ese sentido la oposición considera a la cláusula quinta de la Constitución Nacional como un avance sobre las autonomías provinciales; situación que afecta a los principios del federalismo defendidos por la misma Constitución.

La necesidad de reformar la Constitución está fuera de todo debate, por lo que el bloque de la UCR presenta un proyecto para convocar a elecciones de diputados constituyentes para avanzar con la reforma de la Constitución provincial por entender que «se impone la necesidad de renovación de muchos de sus principios y disposiciones, para ponerlos a tono con el progreso alcanzado en todos los órdenes de la vida». ${ }^{9}$ El proyecto propuesto apunta: «al régimen electoral; la elección directa de gobernador, vice y senadores nacionales; la inamovilidad de los jueces; y la consolidación de los municipios, organizándolos sobre bases que consulten los legítimos intereses de la población». ${ }^{10}$ Reformas parciales, algunas de las cuales recuperan contenidos de la Constitución de 1921 -la misma que en su momento el radicalismo se negó a poner en vigencia-, que apuntaba a una descentralización del ejecutivo provincial a partir de dotar de autonomía a los municipios y comunas mientras jerarquizaba el rol de la legislatura. El proyecto no será tratado en las cámaras y el radicalismo insistirá entonces en su rol opositor, impugnando las formas de convocatoria a la Asamblea Constituyente y presentando un proyecto para declarar la nulidad de la misma.

9- Diario de Sesiones, Cámara de Diputados de la provincia de Santa Fe, 23/06/1949.

10- Diario La Mañana, Santa Fe, 28/06/1949. 
Así, el radicalismo va precisando el lugar de la oposición como defensor del federalismo y la autonomía provincial y de la tradición constitucional local. En nombre de esa tradición, recupera en su propuesta reformista contenidos de la Constitución de 1921 y, al mismo tiempo, defiende los procedimientos establecidos por la Constitución vigente para proceder a su reforma. Apoyado en las dos Constituciones locales que sirven de antecedentes, la vigente de 1900 y la malograda de 1921 -que había tenido una breve vigencia efectiva durante el gobierno demoprogresista de 1932/1935- (Macor 1993 y 1996), el radicalismo puede oponerse a la reforma, por la oportunidad y los procedimientos, sin renunciar a la necesidad de la misma.

El oficialismo peronista responde a la impugnación invocando la Constitución Nacional de 1949, que acaba de ser aprobada y han jurado todos los miembros de la legislatura local al asumir su cargo. Pero además, los legisladores peronistas recuerdan a quienes han sido electos diputados y senadores en la elección del 8 de mayo -y que ahora impugnan la transformación de la legislatura en órgano constituyente-, que fueron electos con el mandato de constituirse en Asamblea Constituyente. Cuestiones que se refuerzan con la visión que el oficialismo tiene acerca del rol del gobierno provincial como agente natural del gobierno federal, que debe arbitrar las medidas para que se cumpla con lo dispuesto por la Constitución Nacional. ${ }^{11}$

Los legisladores peronistas apelan también a la historia como fuente de legitimación de sus actos presentes, cuando recuerdan que la Constitución de 1853 disponía que las provincias debían someter sus Constituciones a la aprobación de la legislatura nacional,

«... cláusula que para nada afectaba la autonomía de las provincias ni al sistema federal, (y que) fue resistida y desapareció de la Constitución Nacional, no por estos factores sino porque en nuestro país se ha considerado que la Nación es única e indivisible y que es preferible llegar a cualquier sacrificio antes que dejar que una provincia se aparte del seno de la unidad nacional». ${ }^{12}$

11- En el decreto de convocatoria el ejecutivo provincial expresa: «Tengo el honor de comunicar a VH que este PE ha dictado el decreto por el cual se convoca a esa Honorable Legislatura para el $1^{\circ}$ de julio próximo a los efectos que en él se determinan... La cláusula $5^{\circ}$ de las disposiciones transitorias de la $\mathrm{CN}$ establece que en el término y en la forma que prevé debe efectuarse la reforma constitucional... Las razones invocadas y el expreso facultamiento conferido por el art. 103 de la $\mathrm{CN}$ al gobierno de la provincia como agente natural del gobierno federal para hacer cumplir esa Constitución y las leyes de la nación, imponen y fundamentan en la emergencia esta convocatoria de excepción, cuyos precedentes se mencionan». Diario La Mañana, Santa Fe, 29/06/49.

12- Diario de Sesiones, Cámara de Senadores de la provincia de Santa Fe, 30/06/1949, p. 157. 
Esta idea de la nación por sobre las parcialidades provinciales se complementa con la noción de "pueblo» que reúne las mismas características -único e indivisible-. Así, se afirma:

«... que en base al sistema representativo y federal, de acuerdo a las normas que imperan en esta democracia, la facultad o la potestad legislativa corresponde íntegramente al pueblo de la nación, al pueblo considerado como una entidad única e indivisible. Pero como el pueblo no delibera ni gobierna sino por intermedio de sus representantes, es natural que haya delegado tales funciones de soberanía en la Asamblea Constituyente de 1949». ${ }^{13}$

Con argumentos que buscan la legalidad remitiendo a Constituciones diferentes, y la legitimidad en concepciones también diferentes, al ponderar unos que la nación está por encima de las provincias mientras los otros destacan que las provincias son anteriores a la nación y de allí derivan la necesidad de respetar su autonomía, se va constituyendo el campo de disputa en torno al cómo y el qué de la reforma constitucional. El cómo, remite a los procedimientos a seguir para viabilizar la reforma; el qué, compete a los temas a incluir en la agenda de la misma.

\section{III.}

En este clima, se abren las sesiones de la Asamblea Constituyente el $1^{\circ}$ de julio de 1949, conformada por 60 convencionales, 43 peronistas y 17 radicales. Los diputados radicales prestarán juramento con las reservas que formularan en el proyecto de nulidad de la convocatoria, proyecto que recién será tratado y rechazado durante el segundo mes de sesiones, ya comenzado el mes de agosto.

Constituida la Asamblea, cierta morosidad ganará a la misma con respecto a la presentación del proyecto de reforma oficial, fundada en los recorridos previos del proyecto que hablan de una fiscalización y control por parte del poder nacional. Como lo expresa el vespertino de la ciudad capital de la provincia:

«En los círculos legislativos se cree que para el martes 12 habrá llegado el proyecto de reformas a la Constitución que ha sido elevado a consi-

13- Diario de Sesiones, Cámara de Senadores de la provincia de Santa Fe, 30/06/1949, p. 156. 
deración de las autoridades superiores de la Nación y del partido». ${ }^{14}$

Tal como lo adelanta El Litoral, el proyecto oficial tiene entrada el 12 de julio. El mismo se organiza en un preámbulo y nueve secciones. ${ }^{15}$ En el preámbulo, se sintetizan los objetivos que movilizaron a la reforma: «de ajustar las instituciones provinciales al nuevo ordenamiento jurídico social argentino». En correspondencia con dichos objetivos, el proyecto presentado incorpora los derechos sociales, reproduciendo íntegramente el artículo 37 de la Constitución Nacional, y la función social de la propiedad, tema al que dedica un capítulo en el que reitera los principios establecidos al respecto en la esfera nacional.

Con referencia a la organización de los poderes del Estado provincial, las innovaciones se plantean en cuanto a la duración de los mandatos y las formas de elección. Todos los cargos, tanto ejecutivos como legislativos, se amplían uniformizándose en seis años. Esta ampliación en el caso del poder ejecutivo, se acompaña de la imposibilidad de reelección inmediata. A la vez, para la elección del gobernador se propone el voto directo, abandonándose el antiguo sistema de colegio electoral. Para la legislatura local, se mantiene el criterio de la representación política con base en la población para la constitución de la cámara de diputados, estableciendo que será elegido un diputado cada 40.000 habitantes o fracción que pase de veinte mil, de acuerdo con la población calculada al $1^{\circ}$ de enero de 1949, y que en ningún caso el número de diputados excederá de 50. Los senadores serán elegidos uno por departamento. Con respecto a los legisladores suplentes, se elegirá uno por cada senador y un 50\% del total de los diputados.

Con referencia al poder judicial, el proyecto mantiene el sistema vigente en la provincia es decir el de la Constitución de 1900 (que comprende: Superior Tribunal de la Provincia y Cámara de Apelaciones de Rosario), al

14- Diario El Litoral, Santa Fe, 09/07/1949.

15- Sección primera 3 capítulos que se titulan: declaraciones generales, derechos, garantías y obligaciones; derechos del trabajador, de la familia, de la ancianidad, de la cultura y el niño; función social de la propiedad, actividad económica y servicios públicos. Sección segunda: capítulo único: Representación política. Sección tercera: poder legislativo, cámara de diputados, cámara de senadores, disposiciones comunes, atribuciones del poder legislativo, de la asamblea legislativa, de la formación y sanción de las leyes. Sección cuarta: poder ejecutivo, de su naturaleza y duración, del tiempo y de la forma en que debe hacerse la elección del gobernador y vice, atribuciones del PE, de los ministros, responsabilidad del gobernador y sus ministros, del fiscal de estado. Sección quinta: capítulo único: del poder judicial. Sección sexta: juicio político. Sección séptima: capítulo único: del régimen municipal. Sección octava: capítulo único: educación e instrucción. Sección novena: reforma de la Constitución. 
que incorpora los Tribunales de Trabajo. En el mismo registro de la Constitución de 1900, la propuesta oficial mantiene el principio de movilidad de los jueces, estableciendo que durarían seis años en sus funciones y podrán ser reelectos. Esta propuesta de continuidad de los términos establecidos a comienzos del siglo para el funcionamiento del poder judicial, será una de las principales fuentes de debate y Ilevará al oficialismo a aceptar parcialmente las críticas de la oposición y rever la propuesta original.

Otro tema, motivo de fuertes controversias, es la propuesta de régimen municipal, aunque el oficialismo mantendrá en este caso el punto más discutido del proyecto original, es decir; la pérdida de autonomía de la ciudad capital de la provincia, tanto por el mantenimiento de lo establecido en la Constitución de 1900 con respecto a la designación del ejecutivo municipal por el gobernador de la provincia, como por la desaparición del Concejo Deliberante, la rama deliberativa del gobierno de la ciudad capital, cuyas funciones serán desempeñadas por la legislatura provincial. Ésta ejercerá a tal fin legislación exclusiva, debiendo sancionar su régimen impositivo y fijar el presupuesto de la municipalidad capitalina. En los demás municipios, se mantienen las dos ramas de gobierno: el ejecutivo, designado por el gobernador de la provincia, y el Concejo Deliberante, para el que se mantiene el carácter electivo. ${ }^{16}$

Con la entrada del proyecto oficial y la posterior presentación y aprobación del reglamento para el funcionamiento de la Asamblea, se ponen en marcha las comisiones de trabajo en las que participará el radicalismo pese al pedido de nulidad que ha presentado. El radicalismo entiende que debe:

«... actuar en las comisiones para poner nuestro punto de vista sobre todos los problemas institucionales sobre las conquistas sociales, sobre las innovaciones en materia institucional, y sobre todo aquello que representa una aspiración popular y que el programa de nuestro partido compendia en su plataforma sancionada por la convención nacional en el transcurso del año 1948... Ese era el motivo por el cual adelantamos que íbamos a firmar en disidencia los despachos respectivos, pero que deseábamos participar de las deliberaciones para que el pueblo de Santa Fe y el de toda la República conozca cuál es el pensamiento de nuestro partido sobre lo que es menester llevar a cabo en materia

16- Convención Constituyente, sesión del 12/07/1949, en: Diario de Sesiones de la Convención Constituyente, año 1949, pp. 12-25. 
de ordenamiento jurídico institucional para estar a tono con la hora, y contemplar las aspiraciones de la masa popular en toda la magnitud de sus proyecciones». ${ }^{17}$

Desde ese lugar de fiscal y acatando disposiciones de las autoridades partidarias, «determinadas por el deber de defender los principios básicos de nuestra organización democrática y representativa», ${ }^{18}$ el radicalismo va a denunciar y rechazar la asignación de dietas para los convencionales constituyentes por entender que la misma no corresponde en la medida que los convencionales ya perciben su remuneración como legisladores. ${ }^{19}$

Así, el radicalismo sienta su posición sobre algunos temas pero se ve imposibilitado en otros por una serie de «desprolijidades» que impiden su concurrencia a algunas de las reuniones en las que se discute el proyecto enviado por el ejecutivo. Esto precipita el abandono de la Convención, dejando sentada la posición del partido en la sesión convocada para la discusión y aprobación de la Constitución. Como lo expresa un convencional radical:

«...concurrimos a algunas comisiones, llenamos nuestra misión en la medida que fue posible realizarla; algunas comisiones a raíz de las informaciones de que disponíamos, no se reunirían pero nos encontramos con que la Comisión Revisora produce un despacho del cual tenemos conocimiento porque se nos remitió por correo en cuya confección no nos fue posible intervenir a raíz que no se nos dio noticia de la reunión de esa comisión...

Entendemos que ello implica un avasallamiento de los derechos de la minoría y un cercenamiento de la función que los legisladores radicales estaban Ilamados a desempeñar en este cuerpo». ${ }^{20}$

El retiro de la oposición deja el camino allanado para la aprobación del proyecto tal como lo propone la comisión revisora. Sin embargo, aún cuando no sea posible el debate en los marcos institucionales naturales por la ausencia del radicalismo, otros serán los lugares por donde se desarrollará

17- Diario de Sesiones de la Convención Constituyente, año 1949, p. 85.

18- Resolución del bloque legislativo del radicalismo, reproducido en diario El Litoral, Santa Fe, 27/07/1949.

19- Diario El Litoral, Santa Fe, 27/07/1949: «... el grupo legislativo de la UCR, consecuente con su posición doctrinaria y adoptando la actitud lógica que se desprende de escrúpulos imaginables ha resuelto con el voto unánime de sus componentes renunciar en forma absoluta a percibir los citados emolumentos, haciendo conocer esta resolución y los fundamentos que la informan al pueblo de la provincia». 20- Convención Constituyente, sesión del 24/08/1949, en: Diario de Sesiones de la Convención Constituyente, año 1949, pp. 85-88. 
el mismo, especialmente en la prensa escrita. En efecto, ya antes del mes de julio, fecha de conformación de la Asamblea Constituyente, y durante las sesiones de la misma, los principales diarios toman partido por algunas cuestiones puntuales.

El diario La Mañana, voz del arzobispado, en una nota que titula «El electorado católico y los comicios», aconseja a sus lectores acerca de cómo deben votar en las elecciones del 8 de mayo convocadas para elegir las autoridades provinciales, entre ellas los diputados y senadores que integrarían la Convención Constituyente:

«El electorado católico, vota teniendo en cuenta las clarísimas instrucciones impartidas por el Episcopado Argentino, hace años. Ellas están por sobre toda bandería política y no tienen sino la única finalidad de que el electorado católico haga un uso consciente de su derecho ciudadano al emitir el sufragio y no olvidando que vota como argentino y como católico y que por consiguiente, ha de meditar acerca de la trascendencia del acto eleccionario». ${ }^{21}$

El diario, que expresa la voz del arzobispado local, inscribe así esta elección en un marco más general, que da cuenta de un proceso electoral de más de una década en que la Iglesia ha fijado posiciones y dado recomendaciones más puntuales a la grey católica a la hora de votar. El diario recuerda a tal fin lo dicho por el episcopado en otras jornadas decisivas como las de las elecciones nacionales de fines de 1931 y las de febrero de 1946.

«Recordemos brevemente lo que dice el Episcopado. El ciudadano católico tiene grave responsabilidad de votar, no debiendo considerar la elección como una obligación sino como un deber moral. En su doble condición de ciudadano argentino y católico, ha de sufragar teniendo en cuenta antes que los intereses de partido, los de la Religión y de la patria. Dice textualmente el Episcopado Argentino: entre varios candidatos o listas aceptables, desde el punto de vista católico, se ha de votar por los que, en conciencia, parezcan más aptos para procurar el mayor bien de la Religión y de la patria, aunque no pertenezcan al partido propio, porque el bien público es superior al bien del partido. Cuando todos los candidatos o listas que se presenten sean inaceptables desde el punto de vista católico, se ha de votar por los menos inaceptables, de cuya actuación se puedan temer menos perjuicios

21- Diario La Mañana, Santa Fe, 03/05/49. 
para la religión y para la patria. Ningún católico puede afiliarse a partidos o votar candidatos que inscriban en sus programas los principios siguientes: 1) La separación de la Iglesia y del Estado, 2) la supresión de las disposiciones legales que reconocen los derechos de la religión, particularmente el juramente religioso y de las palabras en que nuestra Constitución invoca «la protección de Dios, fuente de toda razón y justicia», porque tal supresión equivale a una profesión pública y positiva de ateísmo, 3) El laicismo escolar, 4) El divorcio legal».22

Esta posición, que es un claro apoyo electoral al oficialismo peronista, se refuerza con un abierto respaldo a la nueva Constitución Nacional y al mismo tiempo a la reforma provincial.

«Nuestra provincia si quiere seguir progresando, si no quiere encerrarse en sí misma, esclava del pasado y poco preocupada del futuro, en un aislamiento espiritual además que económico, político y social, debe uniformar su destino institucional con aquél superior de la Nación, para que en armonía de esfuerzos y de conquistas nos dé en el mundo el puesto que corresponde, a los pueblos sabios, justos, fuertes, generosos y deje en la historia una estela de grandeza». ${ }^{23}$

La armoniosa relación de la Iglesia con el poder político nacional y también provincial; así como el acuerdo con los principales lineamientos de la nueva Constitución Nacional y del proyecto de reforma local, explican que se acompañe en esta oportunidad al oficialismo promotor de la reforma, contrastando con el comportamiento asumido por la institución eclesiástica en 1921 y en 1931/1932, cuando las orientaciones reformistas se fundamentaban en la tradición liberal. En esas esferas de la vida social que la iglesia considera como un territorio natural, como la educación y la familia, los textos constitucionales del peronismo oficial tributan lo suficiente a la tradición conservadora como para evitar conflictos con la iglesia por esos temas. ${ }^{24} \mathrm{En}$ nuestro caso local, la Iglesia no tiene una intervención destacada en defensa

22- Diario La Mañana, Santa Fe, 03/05/49.

23- Diario La Mañana, Santa Fe, 02/07/1949. Cf. también, La Mañana, Santa Fe, 17/03/1949; 29/06/1949.

24- Un buen ejemplo del horizonte reformista de 1949 en estos temas, es este artículo de la nueva Carta nacional que es retomado en la reforma provincial: «La enseñanza primaria en las escuelas rurales tenderá a inculcar en el niño el amor a la vida del campo, a orientarlo hacia la capacitación profesional en las faenas rurales y a formar la mujer para las tareas domésticas campesinas» Constitución Nacional de 1949, artículo 37 inciso IV.2. Incorporado en su integridad en el artículo 16 de la Constitución provincial de 1949. 
de la propuesta del oficialismo, sino de manera indirecta o en temas puntuales. Se manifiesta atacando, por ejemplo, a quienes desde la oposición recuperan algunos de los principios liberales de la reforma de $1921 ; 25$ o interviniendo especialmente en el debate público en defensa de temas caros al peronismo. Por ejemplo, sobre la oportunidad de darle rango constitucional a la estabilidad de los empleados públicos, y para dar fundamentos a la propuesta oficial, que no considera necesario el reconocimiento del derecho de huelga a los trabajadores. ${ }^{26}$

Enrolado claramente en el campo de la oposición y primero entre pares desde que el radicalismo se retira de la Asamblea Constituyente, el diario El Litoral da prioridad a otros temas entre los que se destacan el régimen municipal y la forma de constitución del poder judicial, en especial la designación de los magistrados. En el tema municipal, poco podrá hacer la oposición contra el proyecto oficial, que será sostenido sin modificaciones por el bloque peronista en la Asamblea Constituyente. En el tema judicial, en cambio, el proyecto originario del oficialismo, que prácticamente mantenía lo establecido por la Constitución de 1900, recibirá algunas modificaciones en la Convención en la dirección propuesta por la oposición.

En lo que atañe a la cuestión municipal, El Litoral entiende que la adopción de un régimen electivo para intendentes y concejales es una medida fundamental para el funcionamiento de un sistema democrático. En tal sentido en una de las varias editoriales dedicadas a esta cuestión expresa:

«... De todos los aspectos relacionados con la nueva estructura institucional que deberá regir los destinos del $2^{\circ}$ estado argentino, el que se vincula con la vida de los distintos núcleos de población que forman

25- El diario católico La Mañana, por ejemplo, contesta a los diputados de la oposición que se expresan a través del vespertino de la ciudad capital: «Hemos leído en el diario El Litoral del viernes pasado, una declaración del candidato a diputado por el departamento La Capital, Dr. Medrano, perteneciente a la UCR $(\mathrm{CN})$. Este señor se lanza a formular una serie de conceptos acerca de la religión, del clero, de la enseñanza religiosa, etc., viniendo con un cuento viejo con el que no puede engañar a nadie, dado que propugna la neutralidad en materia tan fundamental, neutralidad que los católicos conocemos muy bien. Olvida el Sr. Medrano, o mejor dicho se hace el olvidado de una realidad incuestionable cuando dice estas cosas. Neutralidad en religión, en la Argentina y lógicamente en la provincia de Santa Fe, es postura de lucha contra el catolicismo. Este procedimiento no es nuevo. Lo han usado siempre los liberales y con ello han tenido, muy poco democráticamente, el manejo a su antojo en ciertas cuestiones como estas, marchando totalmente de contramano contra el sentimiento profundamente católico de la inmensa mayoría de los habitantes de nuestro suelo, argentinos y extranjeros». Diario La Mañana, Santa Fe, 24/04/1949.

26- La Mañana, Santa Fe, 07/07/1949; 13/07/1949; 30/07/1949; 12/08/1949. 
las villas pueblos y ciudades, adquiere una importancia fundamental. Un análisis sobre la evolución registrada en el transcurso de este siglo en materia municipal arroja no sólo una aleccionadora experiencia sino también un saldo desfavorable sobre la misma evolución ideológica y política que ha tenido interrupciones tan pronunciadas en las distintas etapas de la vida cívica de la provincia. En este sentido la legislación municipal ha sido y aún sigue siendo el barómetro del adelante y del retroceso político.

... La experiencia señala que si la Convención actúa con amplio espíritu democrático y con un sentido progresista, reconociendo en los municipios el carácter de célula viva de toda democracia bien organizada, el capítulo dedicado al régimen deberá asegurar una absoluta autonomía a las comunas, con intendentes y concejos electivos por el sufragio universal». ${ }^{27}$

Al asignar a la legislación municipal ese carácter fundamental, el diario y los múltiples políticos opositores que opinan desde sus páginas, recuperan una tradición deudora del pensamiento sarmientino, que en la provincia ha tenido un sostén principal en la figura de Lisandro de la Torre. Frente al avance del oficialismo peronista en la nación y en la provincia, un tema como la cuestión municipal, que había enfrentado a radicales y demócratas progresistas en las décadas anteriores, se transforma ahora en bandera común, en un proceso de concentración de la oposición en torno al Partido Radical en tanto mejor favorecido en las urnas.

Como ya anticipamos, el proyecto de reforma presentado por el bloque oficial y que será aprobado por la Asamblea Constituyente, implica un serio avance del poder provincial sobre el municipal: no reconoce el principio electivo para la rama ejecutiva municipal en general en el territorio provincial, y más aún elimina el Concejo Deliberante en la ciudad capital. Mientras que el nombramiento del intendente es responsabilidad del gobernador, la legislatura provincial asumirá las funciones antes conferidas al de la ciudad de Santa Fe.

Con respecto a los poderes ejecutivos municipales, la elección por parte del gobernador es de larga data, de acuerdo a lo establecido en el texto constitucional de 1900. La excepción la introduce la Constitución de 1921, al incorporar a los intendentes entre los cargos electivos. Pero con la reim-

27- Diario El Litoral, Santa Fe, 28/06/1949.

.66. 
plantación de la Constitución de 1900 a mediados de la década del treinta, tal disposición se anula para la rama ejecutiva, manteniéndose sólo el principio electivo para la conformación de los Concejos Deliberantes. Consecuencia insólita: en las localidades más pequeñas las Comisiones de Fomento, integradas por representantes electos por sufragio, retienen la atribución de designar al presidente de comuna; en las ciudades más importantes, en cambio, el responsable del poder ejecutivo municipal es un delegado del poder provincial.

«Aunque resulta paradojal ... de acuerdo con la legislación en vigor en la provincia desde que se estableció la vigencia de la Constitución del 90, los pueblos y villas con menos población han sido administrados de acuerdo con un régimen más progresista y autónomo que el que rige en las ciudades». ${ }^{28}$

Pero lo que resulta toda una novedad para la tradición constitucional local es la supresión del cuerpo legislativo en el municipio capitalino. Se refuerza así la situación paradojal que se señalara con relación a la diferencia entre las ciudades y los pueblos más pequeños de la provincia.

«Una ciudad con casi doscientos mil habitantes, con problemas edilicios y de servicios públicos importantes y difíciles y cuyas soluciones deben arbitrarse mediante la discusión serena no exenta del necesario control popular, no puede ni debe ser administrada como una simple dependencia del gobierno provincial. $\mathrm{Ni}$ al vecindario ni el propio PE les conviene el sistema, como ya lo han advertido las Convenciones de las provincias de Tucumán y Mendoza que con buen criterio y con sentido histórico, no han recogido la recomendación para suprimir las ramas municipales deliberativas en las capitales de sus respectivos estados. Ciudades fundadas hace varios siglos, anteriores a la organización nacional y cuyos cabildos fueron el fiel exponente de las inquietudes del pueblo y de sus afanes por romper los vínculos coloniales y consolidar la paz interior, no pueden ni deben perder esa fisonomía institucional que dentro del régimen republicano acuerda al municipio la característica de célula básica de toda democracia progresista». ${ }^{29}$

Completando esta matriz centralizadora, que en lo concerniente al gobierno de las ciudades tiene su eje en el poder provincial, el proyecto dejaba

28- Diario El Litoral, Santa Fe, 24/07/1949.

29- Diario El Litoral, Santa Fe, 24/07/1949. 
en manos de la legislatura de la provincia la redacción de las cartas orgánicas que debían regir la vida de los municipios.

Sobre la reforma en la esfera municipal, los fundamentos de los diputados del oficialismo en la Convención apuntan en dos direcciones principales. Por un lado, con respecto a la elección de los intendentes por el gobernador, el oficialismo entiende que: "la experiencia de la Constitución del 21, ha dejado un saldo desfavorable; y la subcomisión se inclina por lo conocido y practicado». ${ }^{30}$ Con respecto al gobierno de la ciudad capital de la provincia, el ejemplo es la capital federal, y el fundamento legislativo una superficial referencia al libro El gobierno representativo, de Matienzo. La referencia reproduce un comentario más bien marginal del texto de Matienzo, recordando «que la disolución del Consejo municipal electivo y su reemplazo por comisiones nombradas por el poder ejecutivo, ha podido llevarse a cabo siempre sin protestas del vecindario. Y que en los conflictos suscitados entre el intendente nombrado por el gobierno y el Consejo elegido por parte del vecindario calificado para ello, el pueblo ha inclinado sus simpatías hacia el lado del primero, cuya gestión ha sido, salva raras excepciones, correcta y progresista». ${ }^{31}$ Con esta interpretación, que remite tanto al escrito de Matienzo como a lo legislado para la ciudad de Buenos Aires, el oficialismo agota los fundamentos de su iniciativa.

El otro tema al que la prensa opositora le dedica especial atención es la cuestión judicial. En la provincia, el principio de inamovilidad de los jueces fue incorporado por la Constitución de 1921, vigente entre los años 1932-35; su derogación repuso la normativa de la Constitución de 1900 y con ella la movilidad de los magistrados. La continuidad de este principio establecido en el proyecto del oficialismo, es considerada por la oposición como un retroceso en materia de organización institucional, que contradice incluso la doctrina incorporada a la propia Constitución Nacional, y llaman la atención acerca de los riesgos de una disposición de este tipo:

«El juez por la dignidad del cargo que ejerce y por la importancia fundamental de su función en la sociedad, debe quedar al margen de los cambios políticos. Si la Constitución de un estado no asegura su inamovilidad se consagra una relación de dependencia entre el ma-

30- Convención Constituyente, sesión del 24/08/1949, en: Diario de Sesiones de la Convención Constituyente, año 1949, p. 203.

31- Diario de Sesiones de la Convención Constituyente, año 1949, p. 204.

.68. 
gistrado y el poder que lo designa peligrosa para la colectividad. De ahí que el requisito fundamental para el logro de una buena y perfecta administración de justicia lo constituye sin duda alguna el principio de la inamovilidad de los jueces...». ${ }^{32}$

Sabemos que el peronismo tiene una cómoda mayoría en la Convención; situación que habrá de facilitarle la aprobación de su proyecto de reforma. Más aún, cuando el radicalismo opta por abandonar la Asamblea. ${ }^{33}$ Su retiro no impide la continuidad de la Convención, dada la cantidad de diputados con que cuenta el oficialismo que le permite controlar el quórum. Por el contrario, el retiro del radicalismo facilita la rápida sanción de la nueva Carta constitucional provincial.

A pesar de esta situación, el texto aprobado recoge algunas de las cuestiones que a lo largo de estos meses fueron materia de discusión, y en especial la cuestión del poder judicial. En el texto definitivo, el oficialismo introduce la figura de una Corte Suprema, que no estaba en el proyecto original, e incorpora a la vez una parcial estabilidad de los jueces. La Constitución aprobada establece que el poder judicial de la provincia está compuesto por una Corte Suprema, cámaras de apelaciones y demás tribunales que se establezcan por ley; que esa corte suprema está integrada por cinco jueces y un procurador; y que los jueces de esa corte son inamovibles, es decir que sólo se los puede destituir por juicio político realizado por la legislatura. La designación de los demás jueces tiene un carácter diferente a los miembros de la corte. No son inamovibles, sino que se los considera en igualdad de condiciones que el resto de los empleados públicos a quienes se les refuerza la estabilidad laboral que ya gozan confiriéndole rango constitucional.

\section{IV.}

Cumpliendo con la cláusula transitoria de la Constitución Nacional, la provincia de Santa Fe se da su Constitución. Una gran concentración popular

32- Diario El Litoral, Santa Fe, 09/07/1949. Cf. también la carta enviada por el juez federal Dana Montaño al presidente de la Convención Constituyente, remitiéndole dos trabajos de los que es autor y en los que trata el tema de la designación de los magistrados. Reproducida en: El Litoral, Santa Fe, $02 / 08 / 1949$.

33- Diario El Litoral, Santa Fe, 11/08/1949. «Los radicales se retiraron de la Asamblea constituyente. Se produjo una incidencia que no alcanzó proporciones entre un convencional peronista y otro radical». El Litoral, Santa Fe, 24/08/1949. 
es anunciada por el diario La Mañana para acompañar el juramento de la nueva Carta por el gobernador. ${ }^{34}$ Sin embargo, a pesar del acompañamiento popular -que La Mañana quiere multitudinario-, la ausencia de la oposición le quita a la nueva Constitución ese consenso mínimo que la movilización y apoyo popular no alcanzan a reemplazar.

Del análisis de los acontecimientos, un primer elemento se destaca como diferente de los anteriores procesos de reforma constitucional vividos en la provincia. En el caso que nos ocupa, la necesidad de la reforma viene impuesta desde el ámbito nacional y es parte de un dispositivo mayor de centralización y homogeneización del poder por parte del peronismo. Esto condiciona el comportamiento de los actores que participan en el escenario político, tanto al oficialismo provincial que deberá cumplir con los dictados nacionales, como a la oposición, que en defensa del federalismo y la autonomía de la provincia se refugia en la tradición constitucional para impugnar lo dispuesto por el poder nacional.

En todo este período, el peronismo provincial cumple prolijamente con lo dispuesto desde el orden nacional, sin dejar aflorar los conflictos que anidaban en el interior de la organización. Su tarea reformista se ajusta al diseño nacional que innova en el reconocimiento de los derechos del trabajador y de nuevos roles para el Estado, y aunque de otro tenor, también innova en la supresión del Concejo Deliberante de la ciudad capital. Cuando se aparta de ello, como es el caso de la justicia, lo hace manteniendo la tradición provincial, pero rápidamente vuelve sobre sus pasos y rectifica parcialmente su posición. En otros casos; por ejemplo, en la imposibilidad de reelección a período seguido del gobernador provincial, en abierto contraste con el ejecutivo nacional, los débiles argumentos utilizados en favor de esta postura se justifican en la importancia diversa de los asuntos que cada uno maneja. El límite temporal impuesto al poder local parece ser una respuesta a los arrestos de autonomía del primer gobernador y su Partido Obrero de la Revolución.

Así, la cláusula que impide la reelección del gobernador, el no reconocimiento de las autonomías municipales y comunales; y la amputación de la rama legislativa de la ciudad capital, constituyen parcelas del dispositivo de centralización operado por el peronismo, tanto en el orden interno de la provincia como en la relación subordinada del poder local al nacional.

34- Diario La Mañana, Santa Fe, 27/08/1949.

.70 .

- Revista Quinto Sol, No 8, Año 2004 - 


\section{Resumen}

En los primeros años en el poder, el peronismo va forjando su identidad desde una matriz fuertemente direccionalizada desde el Estado nacional, sometiendo a su control a los estados provinciales y los peronismos locales, que por entonces demostraban ciertos rasgos de heterogeneidad incompatibles con el sesgo que Perón imprimía desde la nación a su movimiento político. Ese proceso alcanza su madurez en 1949 con la reforma de la Constitución Nacional y de las Constituciones provinciales.

En ese contexto, este artículo analiza el proceso de reforma constitucional en la provincia de Santa Fe, considerando particularmente: la tradición constitucional de la provincia, la conflictividad del sistema político local y en especial la que atraviesa al peronismo oficial, y la tensa relación entre el poder local y el nacional.

\section{Palabras claves}

Reforma constitucional de 1949 - peronismo - provincia de Santa Fe - consenso - federalismo.

\section{Abstract \\ Political dynamics and constitutional tradition: the constitutional re- form of 1949 in the province of Santa Fe.}

During the first years in power, peronism builds its identity from a matrix strongly directed from the national State, subjecting to its control the provincial States and the local peronisms that showed certain incompatible features of heterogeneity with the bias that Perón stamped to its political movement from the nation. Such a process reaches its maturity in 1949 with the reform of the national constitution and provincial constitutions.

In that context, this article analyses the process of constitutional reform in the Province of Santa Fe, focusing on the constitutional tradition of the province, the local political system conflicts and especially the one that crosses the official peronism, and the tense relationship between the local power and the national one.

\section{Keys Word}


constitutional reform of 1949 - peronism - province of Santa Fe - consensus - federalism.

\section{Bibliografía citada}

*BOTANA, Natalio y MUSTAPIC, Ana María (1991), «La reforma constitucional frente al régimen político argentino», en D. NOHLEN y L. DE RIZ (comps.), Reforma institucional y cambio político, Buenos Aires, Cedes-Legasa, pp. 45-92.

*MACOR, Darío (2002), «Elecciones, rituales y conmemoraciones en la construcción de la unanimidad peronista, Santa Fe, Argentina, 1946-1955», en: Historia Unisinos, vol. 5, $\mathrm{N}^{\mathrm{o}}$ 4, Sâo Leopoldo, RS, Brasil, Universidades do Vale do Rio dos Sinos, julio/diciembre, pp. 205-241.

*MACOR, Darío (1993), La reforma política en la encrucijada, Santa Fe, Universidad Nacional del Litoral.

*MACOR, Darío (1996), «Una experiencia liberal en los años treinta», en: W. ANSALDI et al., Representaciones inconclusas. Las clases, los actores y los discursos de la memoria, 1912-1946, Buenos Aires, Biblos, pp. 165-198.

\section{Recibido: 23/06/04}

Aceptado: 12/10/04 